\title{
LIDERAZGO RESONANTE Y SU EFECTO DINAMIZADOR EN LA NEGOCIACIÓN ANTE
} CONFLICTOS ORGANIZACIONALES ${ }^{1}$

\author{
RESONANT LEADERSHIP AND ITS DYNAMIZING EFFECT IN THE NEGOTIATION AGAINST \\ ORGANIZATIONAL CONFLICTS
}

\author{
Ramiro Buitrago Acuña ${ }^{2}$, María Hernández Rivas ${ }^{3}$ \& Pedro Hernández Malpica ${ }^{4}$ \\ Alcaldía Bolivariana de Miranda-Zulia-Venezuela/ Universidad Nacional Experimental de la Seguridad. UNES- \\ Venezuela/ Universidad de la Costa (CUC).Colombia
}

RECIBIDO: Agosto 16 de 2016

ACEPTADO: Noviembre 28 de 2016

\section{RESUMEN}

El propósito de la presente de investigación, consistió en dilucidar, así como reflexionar acerca del efecto dinamizador que el liderazgo resonante pudiera ofrecer en la gestión inteligente de las emociones, en escenarios conflictivos, a partir de las consideraciones efectuadas desde la doctrina. Para ello, se utilizó una metodología descriptiva y documental, cuya técnica investigativa fuera la observación de los archivos, documentos públicos y privados indubitados, donde se abordase el fenómeno. Así entonces, a través de la revisión bibliográfica, a razón de la hermenéutica e interpretación, con el propósito de comprender este fenómeno, se encontró como resultado que los líderes resonantes, se muestran como negociadores generosos, tendentes a colaborar, motivados para crear situaciones donde las dos partes negociadoras puedan ganar, ofrecen mejores condiciones para alcanzar un acuerdo. Así mismo, crean un clima donde se facilitan la interacción entre las mismas. Concluyendo que, cuando los líderes abocan sus emociones por conducir a sus seguidores en el progreso, consiguen robustecer patrones comportamentales efectivos entre los miembros de su equipo, contemplando diversas maneras de transigir, por medio de la negociación, alcanzando los objetivos propuestos con eficiencia.

Palabras clave: Gestión de las emociones, liderazgo resonante, negociación.

\section{ABSTRACT}

The purpose of the present investigation is to elucidate, as well as to reflect on the invigorating effect that resounding leadership could offer about the intelligent management of emotions in conflictive scenarios, based on considerations made from the doctrine. For this, a descriptive and documentary methodology was used, whose research technique was the observation of archives, undisclosed public and private documents, where the phenomenon was tackled. Thus, through a bibliographical review, on the basis of hermeneutics and interpretation, in order to understand this phenomenon, it was found that resounding leaders, who are also generous negotiators, tend to collaborate, provoking the creation of situations where the two negotiating parties can win, offering better conditions when an agreement is attained. Likewise, they create a climate where interactions between them are duly facilitated. As a conclusion, it may be said that when leaders shed their emotions by driving their followers in progress, they are able to strengthen effective behavioral patterns among their team members, contemplating various ways of compromising, through negotiation, by achieving the goals effectively.

Keywords: Management of emotions, negotiation, resonant leadership.

\section{Este artículo se puede referenciar}

Buitrago, R., Hernández, M. \& Hernández, P. (2017). Liderazgo resonante y su efecto dinamizador en la negociación ante conflictos organizacionales. En Desarrollo Gerencial Revista de la Facultad de Ciencias Económicas Administrativas y Contables de la Universidad Simón Bolívar-Colombia, 9(1), 97-111.

\footnotetext{
${ }^{1}$ Artículo derivado de la investigación intitulada "Liderazgo Resonante como factor propulsor de Negociaciones ante conflictos organizacionales"

2 Doctor en Ciencias Gerenciales, Magister en Gerencia de Recursos Humanos, Abogado, Investigador Independiente, abogbuitrago86@gmail.com.

${ }^{3}$ Doctora en Ciencias Gerenciales, Magister en Ciencias de la Comunicación, Docente Investigador, Universidad Nacional Experimental de la Seguridad - UNES, maryfer_mm@hotmail.com.

${ }^{4}$ Doctor en Ciencias Gerenciales, Magister en Gestión Pública, Magister en Ciencias Jurídicas, Docente Investigador, Universidad de la Costa CUC, phernand9@cuc.edu.co.
}

Desarrollo Gerencial, 9 (1) Pp. 97-111 Enero-Junio 2017. ISSN: 2145-5147 (On Line). Universidad Simón Bolívar. Barranquilla-Colombia. Contactos: desarrollogerencial@unisimonbolivar.edu.co 


\section{INTRODUCCIÓN}

Actualmente, para poder estudiar la negociación, inicialmente se debe tener una idea clara, tangible de esta, con perspectiva científica, y así lograr entender el comportamiento entre individuos integrantes a la misma organización, en la búsqueda de satisfacer necesidades propias o generales. Del mismo modo se sustenta la gestión de las emociones en dicho proceso, a través de la teoría de diversos autores, capaces de ofrecer el enfoque individual, referido al respecto, para que así dicha figura, logre ser vinculada al estudio de patrones comportamentales individuales o sociales.

Podría inferirse entonces, en el abordaje del liderazgo resonante, este puede percibirse, como un elemento importante en la gestión de personas, lo cual hace necesario su conocimiento, dominio; comprensión, siendo así, podría vislumbrarse la posible relación entre éste y otros aspectos de la gestión empresarial, entre los cuales quizás se contaría la negociación, como una de las diversas formas de resolver los conflictos internos en la actividad gerencial del sector público y privado, así también, es necesario en el desarrollo del presente artículo, entender tales o cuales son las emociones con origen endicho proceso, de esta forma quienes dirijan la organización, podrían desarrollarles de modo ideal, haciendo prosperar en su capital intelectual la satisfacción personal, laboral, universal.

$\mathrm{Al}$ respecto, Goleman (2004), citado por Moreno \& Torres (2008), define al liderazgo resonante, como aquel que sintoniza con los sentimientos de las personas, al mismo tiempo que los encauza en una dirección emocionalmente positiva. Esto se traduce en una empatía propia entre el líder y el liderado, haciéndolos sentir muy bien, garantizando de alguna manera un resultado efectivo. Así entonces, Para Galíndez (2011), un buen líder, debe saber escuchar, para así poder encontrar a las verdaderas personas, viendo más allá de las apariencias. Por otro lado, quien se autoproclame como aprendiz, debería aspirar a ser un verdadero guía para sus seguidores. En cualquiera de los dos roles, son fundamentales cuestiones como la ética y el coraje para vivir, generosidad para convivir y prudencia para sobrevivir.

Ciertamente, en este concepto se infiere con facilidad, que se está hablando sobre la persona como líder organizacional, escenificado en el contexto laboral y las relaciones con origen en ello. Así entonces del liderazgo ejercido, se desprende el estímulo ofrecido a sus seguidores, por ello Fernández (2012), destaca, el bien común en la gestión del talento humano, donde a través de la ética, satisface, no solo las necesidades, requerimientos y expectativas de los inversionistas, y clientes, también, por medio de la internalización, procura proporcionar el mayor bienestar y desarrollo hacia todos los grupos de interés vinculados a la empresa, especialmente a sus trabajadores.

Según Maslow (2005), citado por Tocón (2014), el liderazgo nace de las necesidades humanas, siendo estas su motor. Las relaciones entre personas, siempre consisten en un complejo entramado de poder, 
jerarquía, dominación, una de las formas más importantes y efectivas para hacer que un vínculo entre individuos funcione, es la del liderazgo. Por su parte, Meza y Olmos (2014) consideran que el liderazgo, implica generar lealtad, cumplir los compromisos y obtener respeto, la gente que es difícil de supervisar, que tiene la libertad de salir de la organización, que piensa por sí misma, que cuestiona la autoridad, son las mejores fuentes de información y la única esperanza de alcanzar las metas organizacionales. Sin embargo, Para Nava, Seijo \& Mier (2014), los valores y principios, son elementos de importancia, para las personas y organizaciones, estos confieren un halo propio al entorno, determinando las formas de ver la vida, siendo influenciados por las actuaciones, así como juicios de la gente, en los diferentes escenarios en donde actúan.

Ahora bien, la inteligencia social, orienta la forma en que el liderazgo organizacional encuentra un sitio en las corporaciones modernas. Los códigos rígidos de conducta, las reglas y normas inquebrantables, han cedido su espacio a posturas andragógica, que persiguen entre otras cosas posicionar al hombre por encima de otras consideraciones, a través de la comunicación, las emociones se muestran realmente decisivas a la hora de perfeccionar los resultados, tanto del trabajador individualmente, como del área en que labora. Según Parra, Rojas \& Arapé (2008), todo proceso de comunicación, trae consigo la posibilidad del conflicto, pues con cada persona que se entable algún tipo de comunicación está presente esa posibilidad.

Para Goleman (2004), citado por Moreno \& Torres (2008), en el novedoso concepto del liderazgo resonante, se manifiesta la relevancia de las emociones ante las habilidades técnicas de los líderes, teniendo como hipótesis que los directivos actuales, mantienen conductas diferentes en comparación con gestiones anteriores, donde al gerente, se le catalogaba como un ser indiferente ante los problemas, sin sensibilidad alguna, duro, inflexible, egoísta, desorganizado. Por su parte el líder resonante, se muestra abierto, organizado, afectivo, responsable, todo lo cual apunta a un modelo mejor concebido, más estable, sereno, definido.

Igualmente, es importante recordar, que una de las cualidades naturales de estos líderes arriba referidos, es cohesionar, con el amor natural percibido en donde esté, en el trabajo, junto a los amigos, la universidad, o un almuerzo, compartiendo, cohesiona, porque tiene la capacidad de tolerancia latente, por lo cual es importante ser capaz de poder involucrarle en escenarios de negociación. Por ello, El Kadi \& Martínez (2015), plantean, cada proceso de negociación y mediación debe ser caracterizado por la presencia de un objetivo clave que permita unificar criterios y coordinar los esfuerzos entre los distintos individuos involucrados para su consecución, y llevar un estado actual a otro deseado a través de la utilización de algunas estrategias, actividades y acciones que faciliten su cometido. 
Para Vicuña, Hernández, Paredes \& Ríos (2008), la negociación es un medio alternativo de resolución de conflictos entre las personas, las organizaciones e instituciones, sin la presencia de terceros, donde las partes en conflicto exponen y defienden sus puntos de vista. Constituye un proceso de comunicación, a través del cual ellas mismas dan solución al problema llegando a un mutuo acuerdo que privilegie sus intereses. Quizás entonces, actualmente pudiera contextualizarse a las empresas en una época en la que casi todo se negocia. Esta se encuentra, sin discriminación de los grupos sociales, como una forma de relación permanente.

Por ello, el liderazgo resonante, puede lograr un cambio en las personas, propiciando la comunicación fluida, sosteniendo relaciones interpersonales empáticas y estables, consiguiendo la mejor respuesta desde cada trabajador, todo lo cual pudiera ser natural, entendiendo la psicología de este líder, que al gestionar las emociones en la comunicación, debate, negociación, puede lograr con mayor claridad, estabilizar los estados emocionales de quienes integren su equipo. Para González (2008), cuando se plantea el tema de negociación, intelectualmente se plantea un esquema temporal en el que se cruzan, el conocimiento del pasado, y la posibilidad de un futuro, como utopía de una nueva forma de coexistencia. El presente, une al conocimiento del pasado, para crear nuevos escenarios.

De acuerdo con Ovejero (2004), y Fisas (2005), citados por Núñez, Salón, Romero \& Rosales (2009), el conflicto es un proceso interactivo que se da en un contexto determinado; una construcción social y creación humana diferenciable de la violencia, en tanto puede haber conflictos sin violencia pero no intimidación sin contienda, pudiendo ser positivo o negativo según cómo se aborde. Por ello, Ferrer, Acevedo \& Clemenza (2010), plantean, que los líderes eficaces dentro del contexto organizativo, son formadores que dirigen sus esfuerzos a través del apoyo, la sensibilidad, vocación de servicio, el otorgamiento de facultades y poder, mismo otorgado por la comunidad de interés, basándose en la transparencia organizativa..

Ahora bien, con relación a lo antes descrito, los líderes resonantes son seres muy sensitivos, en grupos de trabajo, son capaces de identificar cuáles son las emociones comprometidas en la negociación, gestionando sus emociones con facilidad, logrando involucrarse en el halo emocional de la otra parte, misma con la cual deba negociar la resolución de algún conflicto organizacional. Según Díaz \& Lozano (2010), citados por Díaz (2012), la ética actual es una ética inteligente, donde los individuos que integran las empresas, están abiertos a adoptar nuevos paradigmas, en pro del desarrollo sostenible, lo cual es necesario para la estabilidad económica generada por las organizaciones, como plan de negocio a largo plazo, misma en la que el liderazgo de la alta gerencia, se ve manifiesto en cada proceso.

En este orden de ideas, el liderazgo ejercido con base a las emociones, en muchos aspectos suele tener influencia en diversos factores del escenario organizacional, tanto en empresas pertenecientes al sector 
privado, como a la administración pública, por cuanto se han señalado las cualidades y habilidades propias de los lideres resonantes en su ejercicio del poder, para Fernández, Seijo y Marín (2010), la realidad en el mundo empresarial muestra lo contrario, son muchas las compañías que actualmente hacen pública y manifiesta su postura ética, siendo pocas las que se abstienen a comentar sobre su responsabilidad con el medio ambiente y el bienestar de sus empleados, o en su defecto el apoyo a las comunidades vecinas de la organización.

Por otra parte Portillo \& Buitrago (2015), las organizaciones en el mundo actual, atraviesan una vorágine de renovaciones y transformaciones complejas, novedosas, desafiantes, Por ello, los trabajadores, empresarios protagonizan diversos y diferentes escenarios, que en muchas veces no saben manejar, temerosos, limitados en su accionar natural, lo cual les estanca ante la expectación, del acontecer social, económico, político, cultural; cuestión que pudiera anclarles en su micro entorno, evadiendo así el contexto real que les corresponde vivir, experimentar, conquistar.

Para Cantón \& Arias (2008), ¿Estamos ante un liderazgo administrativo-emocional?, la dirección y liderazgo fundamentada en principios éticos y valores, así como el mantenimiento de relaciones basadas en la satisfacción del personal, resolución de conflictos y estabilidad, fundamentados en la continuidad, tranquilidad e inconcreción, a lo que surja, a lo que los demás deseen. De lo expresado en los párrafos anteriores, florece entonces el interés por generar una investigación analítica, reflexiva, documental, donde se exploren ¿de qué forma pudiera el liderazgo resonante dinamizar los procesos de negociación ante el acaecimiento de conflictos en el contexto de las organizaciones pertenecientes modernas?

\section{MÉTODO}

\section{$\checkmark$ Diseño}

El presente artículo, se realizó bajo el enfoque epistémico cualitativo, con método hermenéutico, del tipo descriptivo y documental, empleando la observación indirecta como herramienta de medición, aprovechando datos estadísticos ofrecidos por investigaciones previas, proyectando así nuevas inferencias, planteando la interpretación, y abstracción crítica del tema abordado.

Se considera por tanto, reflexivo y documental puesto que se apoya en la interpretación, hermenéutica y dialéctica de los planteamientos concebidos por escritos, documentos y otras publicaciones en las que diversos autores exponen las bases teóricas de sus hallazgos. En cuanto a los estudios documentales, Sierra (2008), plantea que consisten en el análisis de informaciones basadas en documentos, los cuales se organizan para dar origen a un nuevo conocimiento, tomando como referencia escritos válidos para el estudio. 


\section{$\checkmark \quad$ Participantes}

Se analizó una serie de publicaciones científicas, de diferentes bases de datos de impacto, así mismo, otros textos que atendieron al liderazgo como fenómeno sociocultural y humano. Por otro lado se enfocó, de forma ontológica y epistémica, en el entendimiento y comprensión del liderazgo resonante como soporte efectivo para la gestión de las emociones en la negociación y resolución de conflictos organizacionales.

Con relación a lo anterior, se consideró al liderazgo resonante, como fenómeno potenciador de los procesos con lugar en las organizaciones modernas tanto las del sector público, como del privado, describiendo sus características fundamentales apoyándose en la revisión bibliográfica documental. Destacando cómo cuando los líderes abocan su energía, por conducir a sus seguidores en procesos de negociación, consiguen resolverles de forma efectiva, facilitando con ello, el alcance de los objetivos propuestos. Al respecto, Sabino (2006), plantea que las investigaciones descriptivas se proponen conocer grupos homogéneos de fenómenos para establecer una descripción de sus características.

\section{$\checkmark$ Procedimiento}

Asimismo, el diseño de investigación de este artículo reflexivo se apoyó en la revisión de bibliografía pertinente al área. Se seleccionaron distintos artículos indexados, publicaciones científicas, en su mayoría, como apoyo indubitado para la elaboración de un nuevo documento, que ofreciera teorías emergentes con relación al liderazgo resonante ejercido en las organizaciones públicas y privadas, así como su impacto en las negociaciones y su resolución. A lo cual Sabino (2006), indica que se fundamenta en la recopilación y análisis de contenidos documentales, los cuales se analizan mediante técnicas documentales.

\section{RESULTADOS}

La formación en negociación, y su práctica, incrementa una serie de competencias sociales, emocionales, básicas que pueden estar presentes, adormecidas o disminuidas por las situaciones de rutina, desmotivación, quizás, situaciones u acometimientos fatigosos. Este líder resonante, desarrolla, entre otros, el comportamiento asertivo. Para Buitrago (2016), muchas organizaciones modernas persiguen encontrar en sus filas líderes ajustados a sus necesidades y aspiraciones, ello, resulta costoso, complejo, extenuante, también, ofrece oportunidades al desconcierto, obstaculizando procesos de búsqueda, advirtiendo que el liderazgo es un don con el que se nace, no es solo deseándolo que se ejecutan a la perfección acciones de líder, de instruir estrategias propias de la dirección estratégica innata.

En consecuencia, la asertividad permite decir lo que se piensa y actuar en efecto, haciendo lo más apropiado para el ser mismo, defendiendo los propios derechos e intereses, sin agredir a terceros, permitir 
agresiones, insultos, evitando situaciones de ansiedad, pudiendo verse reflejado en el lenguaje hablado, corporal, los ademanes, gestos del cuerpo, expresión facial, incluso su voz.

\section{4.- DISCUSIÓN}

Para Zarco \& Rodríguez (2005), las últimas décadas han estado marcadas por numerosos y profundos cambios, aunado a la creciente complejidad de la economía, interdependencia de los mercados, altos niveles de competitividad, incorporación de nuevas tecnologías, entre otras, que han afectado, como no podía ser de otra manera, al mundo del trabajo y de las organizaciones.

Según Arteaga \& Ramón (2009), hoy en día, es universal el precepto de que el éxito de las organizaciones se fundamenta en su capacidad para adaptarse satisfactoriamente a los nuevos desafíos, y por ende, a la existencia en las mismas de un líder que las lleve por el camino más acertado. Es así, como muchas de estas, intentan incorporar poco a poco, nuevos modelos organizacionales, llegando a crear estructuras menos rígidas, en las cuales la imagen del gerente está siendo reemplazada por la figura del líder.

Lo anterior, conduce a imaginar contextos que traspasan las fronteras organizacionales, llámese, social, familiar, empresarial, cultural, científico, político, artístico. Para Buitrago y Portillo (2014), el liderazgo es un proceso que implica además de la capacidad en la toma de decisiones, la habilidad de desarrollarse de la mejor forma, alcanzar las metas propuestas, entre tanto se sostenga y prospere la motivación desde distintos enfoques, el éxito del liderazgo organizacional, refiere a muchos aspectos psicológicos, culturales, sociales y hasta personales. Pudiendo transformar su entorno de adentro hacia afuera, influyendo de modo comunicacional, espiritual, destacando estas destrezas como dirigentes naturales, desarrollándoles aún más luego del ejercido el poder.

Al respecto, Goleman (2004), citado por Arteaga \& Ramón (2009), establece que cuando los líderes encauzan sus emociones y las de sus seguidores en una dirección positiva, provocan un efecto fácilmente difundido sobre estos, al cual se llama resonancia, derivado del término resonar, de allí se considera al liderazgo resonante, en relación con las competencias emocionales del líder, implicando la capacidad del mismo para sintonizar con los sentimientos de las personas, conduciéndolos en una dirección emocionalmente positiva. Siendo la abstracción, el escenario donde dos personas sintonizan en la misma onda emocional, prolongándose este tono efectivo, hacia el logro de los objetivos.

Entre tanto, este modelo de gestión, pudiera convertirse en un marco de referencia para la administración de las entidades en que se practiquen las negociaciones, como formas alternas a la resolución de conflictos organizacionales, estos patrones pueden ser ejercidos tanto en organizaciones del sector privado, como instituciones públicas, en donde este líder resonante participe, otorgándosele un rol 
protagónico de forma y de hecho. En ello, el desarrollo de la inteligencia emocional, así como de las habilidades sociales, permitiría a estos, así como a todos en general, superar el conflicto de poderes típicos de la sociedad, propiciando un espacio en el que ellos también logren su propia realización personal.

Para Tocón (2014), los líderes resonantes son personas capaces de contagiar a los miembros de organización, estimularlos y movilizarlos, canalizando las emociones de cada una de las personas, provocando un clima favorable a la organización. El líder resonante, tiene la habilidad de conciliar las características de todos los estilos de liderazgo, visionario, coaching, afiliativo, democrático; todos estos se basan en un conjunto de competencias emocionales diferentes según sea el caso, manteniendo siempre una conexión con sus seguidores prolongando el tono emocional positivo.

En tal sentido, se infiere que este liderazgo, orienta el poder según sus perspectivas psíquicas, sociales, culturales e intelectuales, todo lo cual lleva a las organizaciones a un nivel de confianza y autodesarrollo más evolutivo, sostenible a cualquier otro, siendo importante la manifestación de los rasgos de su personalidad Entre tanto, para Buitrago (2015), el líder fundamenta su ejercicio del poder en la equidad, participación, comunión de ideas, su relación con los seguidores; seres humanistas que se reafirman como empáticos, sociables, comunicativos, catalizadores del cambio, asegurando así el éxito organizacional. Por ello, la gestión de las emociones en la negociación debe considerar este estilo en su aspiración por ser cada día más eficientes en la resolución de conflictos organizacionales.

Entre tanto, es válido resaltar que los líderes resonantes, se muestran como negociadores más generosos, tendentes a colaborar, motivados para crear situaciones donde las dos partes negociadoras puedan ganar, ofrecen mejores condiciones para alcanzar un acuerdo. Así mismo, facilitan la interacción entre las mismas. Por ello, es válido destacar que el líder resonante, tiene claros enfoques consultivos, cooperativos, la habilidad para combinar, reconciliar expectativas, experiencias contradictorias, promoviendo el compromiso colectivo de los miembros de la organización, desarrollando políticas de cuidado, otorgando mayor atención a los sentimientos, al uso de recursos emocionales, motivacionales, estos son más sensibles a las emociones, así como a las situaciones personales de los demás con una manera única en cada contexto.

Podría inferirse, que estos líderes se caracterizan por crear un clima familiar de gestión y colaboración en el grupo, propiciando la cohesión, así como los vínculos entre los miembros, alentando a otros a compartir los recursos, les preocupa el abuso de poder, son generadores del cambio, motivan a los demás a participar, ofreciendo elementos enriquecedores de los procesos organizacionales. Para Velásquez, Guaiquirima \& Seijo (2011), Se trata de un ethos cuya exigencia radical es que cada hombre sea tratado como una finalidad. Así se constituirá una comunidad integral, armónica de encuentro entre finalidades, justa y realizadora de lo humano. 
Según Caldeira (2016), el liderazgo presume la acción de profesionales con suficientes conocimientos técnicos, información de calidad y experiencia para conducir con éxito a sus seguidores, ha de ser imaginativo, diligente, esforzado, con la organización y su estructura, capaz de involucrar al grupo en la consecución de los objetivos. Finalmente, los líderes resonantes, están más interesados en encontrar una vía para que los involucrados en el conflicto ganen, esta forma de actuar, es especialmente importante en escenarios conflictivos. Por ello, este liderazgo podría alcanzar puestos de responsabilidad en ciertas divisiones que implican cuenten con tales recursos, como en banca, finanzas, obras sociales, altruismo ecológico, medios artísticos o culturales.

\section{Apología de las emociones en la negociación de conflictos: una perspectiva reflexiva y atemporal en momentos de tribulación global}

Entendiendo la negociación como un proceso humano, es posible inferir en ella la manifestación de diversas emociones, advirtiendo que las personas, son estructuras apoyadas en ápices orgánicos y psicológicos, el rol exhibido por estas dentro del debate, el encuentro, desencuentro de hombres, mujeres, es determinante, tanto en el inicio, desarrollo, como conclusión de intercambios entre estos, su importancia estriba, en el hecho de ser reconocida como la estrategia, mas inclusiva, efectiva y eficiente orientada a la resolución del conflicto con origen en los escenarios organizacionales.

Aun así, en la resolución de estos procesos, puede resultar inadecuado el intentar reconocer las emociones en otros, pues el fin esencial de la componenda, es satisfacer necesidades de quienes intervengan en ella, identificando, comprendiendo, controlando factores como la persuasión, manipulación en las percepciones de quien se enfrente, en ese miso orden, es menester destacar, que no es intentando inducir a otros como se realiza una negociación hermosa, sino más bien, extendiendo puentes de comprensión entre posturas, como al ceder, pactar, lograr obtener la aceptación entre las partes, es cuando se puede hablar de una resolución exitosa.

Al respecto, Fernández (2012), plantea, el reto de un negociador está en reconocer y afrontar la emoción, propia o de los otros. En la comunicación oral, la no verbal, es así, cómo al delatarse a través de los gestos, se hace determinante una gestión efectiva, clara, dúctil de las mismas. En este sentido resalta, para un gestor, la importancia del estudio, análisis de la comunicación gestual, principalmente, a fin de poder interpretar en los gestos, las expresiones; los sentimientos de terceros intervinientes, pudiendo controlarlos a favor del convenio.

Ahora bien, puede inferirse del planteamiento anterior, que el éxito en la negociación, no está en negarse a experimentar emociones durante esta, en ese mismo orden, al reconocer las propias, y la de terceros intervinientes, puede lograrse el esclarecimiento de posturas exteriorizadas por las partes, lo cual facilitaría aún más, llegar a feliz término en dicho encuentro, satisfaciendo siempre la necesidad de las 
partes intervinientes, así como la ambición en el control de las emociones experimentadas por su antagonista, pudiendo favorecer el resultado, con relación a las aspiraciones en alguno de ellos al inicio del debate.

Para Núñez \& otros (2009), la inteligencia emocional y la intuición son tan importantes en la vida del hombre, individual, organizacional, social, como lo es la agudeza racional; en su conjunto, ellas le facultan para sobrevivir, ser feliz, exitoso, así también, en convivencia pacífica. Estas inteligencias o saberes, le permiten enfrentar sus conflictos intrapersonales e interpersonales. La organización, como gran comunidad de objetivos claros al centrarse en la persona, mediante el liderazgo, es responsable de crear una cultura de paz, para manejar adecuadamente las situaciones de apremio; para ello, cuenta con arreglos puntuales, así también, desarrollos del discernimiento emocional, la percepción.

Según Vicuña \& otros (2008), en los conflictos pueden distinguirse dos componentes, el primero es el subyacente a las conductas de carácter natural, correspondientes a las emociones, el segundo elemento, son los disparadores o los iniciadores de la conducta conflictiva, los cuales el común de los casos suelen ser aprendidos, por ejemplo el cine, el teatro, en un inicio son neutrales no generan reacción emocional, pero la experiencia con ellos, se habrán conectado a otros estímulos que sí producirían emociones placenteras, como las golosinas, la compañía, el espectáculo en sí mismo, desencadenando reacciones emocionales logrando con ellos adornar de color, aroma, temperatura, a tales acontecimientos.

Asimismo, en el proceso de negociación, las emociones con lugar, son de índole diversa, las mismas enriquecen el proceso, así como también pueden hacerlo más fácil, mientras estas no sean contrarias a su curso, por ello la experiencia influye sobre el desarrollo del debate, en gran medida, con relación a quien este acostumbrado a negociar, comprendiendo con facilidad sus estados de ánimo, gustos, e intereses al estar ubicado en tales escenarios, en caso opuesto, más allá de sentirse confundido, así entonces el negociador estaría en apuros al desconocerse, lo cual le inhabilitaría manejar una situación donde ni el mismo se aprecie cómodo.

Igualmente, Calderón (2004), establece que la efectividad de la negociación todavía se cuestiona desde diferentes campos, pues, es un proceso realmente complejo, donde no existen reglas fijas. Para tener éxito, el negociador debe intentar la máxima racionalidad, controlando las emociones, no dejarse llevar por los impulsos y en cada momento posible poner en práctica, las estrategias analizadas anteriormente. Lo más importante en cualquier debate de este tipo, es lograr convencer a la otra parte de procurar satisfacer los principios e intereses comunes, esto, producirá resultados positivos.

Indistintamente, esta inteligencia emocional juega un rol importante en el proceso de negociación, pues está estrechamente vinculada al reconocimiento y control de las emociones, así también, la inteligencia social, se erige como aquella habilidad donde los sentidos, el raciocinio, la razón, se conjugan en 
escenarios sociales, siendo dicha negociación uno de estos, por ello, tales agilidades corresponden a la evolución en las técnicas empleadas en el debate, advirtiendo el enlace de tales destrezas, las cuales lograrían un beneficio a quienes intervengan en ella con atención a sus necesidades, aspiraciones o propósitos.

Sobre el tema, Fisher \& Shapiro (2007), citados por Fernández (2012), establecen que, en un proceso de negociación los sentimientos pueden estar por encima de las palabras, sobre todo si existen fuertes desacuerdos, y puntualizan cinco aspectos a considerar. En primer lugar, reconocer, comprender las emociones; en segundo, procurar hacerlas explícitas, contemplarlas como legítimas; tercero, permitir a la otra parte desahogarse; cuarto, no reaccionar ante un estallido emocional, por último, utilizar gestos simbólicos, refiriéndose a detalles o actos conducentes a un impacto emocional constructivo en la otra persona, por ejemplo, la entrega de un obsequio.

Ahora bien, según lo expuesto por los autores anteriores, las emociones pueden resultar aún más importantes que la palabra expresada, lo cual es interesante, cuando en la actualidad, se ha presenciado una vorágine de nuevas propuestas, atinentes a la búsqueda del conocimiento, encuentra en las neurociencias, la respuesta a tribulaciones propias u organizacionales, satisfaciendo quizás el interés, por comprender la complejidad del ser humano. Así entonces, al indagar sobre las apreciaciones sociales sobre factores emotivos, es común encontrar escenarios donde puedan ser bien recibidas, sin embargo, habría distintas oportunidades donde no sería así.

\section{El líder resonante, una propuesta de innovación en la negociación oportuna de crisis organizacionales puntuales}

La gerencia de las organizaciones modernas, está en una época de incertidumbre, de cambios, e innovaciones complejas, fecundas, desenfrenadas, donde todo pasa de un extremo a otro constantemente, en esos escenarios muchos gerentes podrían confundirse en la gestión de las organizaciones. En ese mismo sentido, es responsabilidad de estos últimos, retomar el cauce de las aguas que fluyen en el interior de su organización, para sacudir con firmeza, esta polvareda de polillas orientadas a la ambigüedad, y con ello lograr la claridad, iluminando así el horizonte de su gestión.

Para Contreras (2008), el liderazgo, como fenómeno complejo, ha sido entendido desde distintos enfoques, así como corrientes epistemológicas, con impacto en determinado momento, ajustadas a los cambios históricos y culturales en los que se escenifican. Por ello, su conceptualización, tanto el propósito de formar líderes, ha generado, un hecho epistemológico un tanto ambiguo y transitorio, modificándose según los intereses sociales del momento, a la par de las tendencias teóricas vigentes. 
Igualmente, infiriendo que tanto la equidad, como el incremento de la participación de los líderes en los ámbitos laborales, sociales, políticos, son requisitos indispensables para emprender un arduo camino, procurando minimizar los niveles de conflicto, en muchos casos, consecuencia de la ignorancia, limitando el desarrollo integral de este líder en las esferas organizacionales, públicas y privadas. La participación de los dirigentes resonantes en estas organizaciones se hace notable, abriéndose camino en actividades cuya trascendencia correspondía tradicionalmente a otros patrones de liderazgo.

Para Argandoña (1999), el directivo líder, es quien logra que sus colaboradores hagan lo que les manda, no por imposición o conveniencia propia, sino por estar convencidos, de que este entiende lo que les vendría bien, esto es entendido como el saber que este, tiene los conocimientos suficientes como para tomar las mejores decisiones, también pues, ostenta dotes de gobierno ajustadas al escenario, y finalmente, porque comprenden que todo cuanto este propone lo hace pensando en el bien común. Por ello, Según Kadi \& Acevedo (2014), los nuevos líderes deben ofrecer argumentos para convencer a su equipo de las tareas a desempeñar, los objetivos a alcanzar, facilitando, apoyando el trabajo de su gente, generando proyectos que ilusionen y aportan sentido al trabajo de los demás.

\section{5.- CONCLUSIÓN}

Concibiendo el liderazgo resonante, como el conjunto de habilidades individuales e interpersonales y de conocimientos que posee el líder, para lograr propósitos propios u organizacionales, partiendo de la gestión de las emociones, se puede inferir que estos poseen cualidades inspiradoras de manera innata, siendo responsables, expresivos, comunicadores, comprometidos, creativos, emprendedores, visionarios, arriesgados, perseverantes, constantes, sensibles; con habilidades interpersonales, siendo solidarios e integradores, participativos, que disfrutan trabajando en equipo, generando iniciativa en sus seguidores.

Asimismo, el líder resonante, demuestra compromiso con las partes, en el caso concreto de una negociación, éste, cobra sentido sólo si realmente cree en lo que hace, esto es, si existe certeza real de sus competencias, habilidades, destrezas. En este sentido, el plano social de la actividad desarrollada adquiere cierta relevancia. Ahora bien, si el líder no está convencido del trabajo realizado es el mejor o al menos, aporta beneficio a quienes estén interesados y vinculados a este, será difícil lograr un grado óptimo de confianza de quienes hagan parte en la negociación, con lo procurado, la solución del conflicto organizacional.

Así también, los líderes resonantes, manifiestan un pensamiento integrador, de los entornos, sus estructuras, elementos determinantes, así como quienes estén involucrados en la gestión de las emociones al procurar resolver conflictos organizacionales. Su enfoque reflexivo se muestra multisectorial, al inferir sobre el éxito, convergen en ello carrera, familia, comunidad, aspectos personales, así como el comportamiento y respuesta emocional de sus seguidores. Asimismo, traen consigo, esta visión integral a 
las s organizacionales, independientemente de que estas pertenezcan al sector público o privado, en pos de la resolución de problemas, yendo más allá de los hechos, toman en cuenta los valores, la visión, la cultura y las relaciones.

Igualmente, puede inferirse que el liderazgo resonante, con atención al cambio de época, se hará cada vez más un elemento profundamente determinante en el éxito de las negociaciones, o cualquier otro proceso en donde se aspire a resolver conflictos estructurales al interior de las organizaciones, e incluso fuera de estas, con relación al capital relacional, o grupos de interés que pudieran tener alguna vinculación con las disputas abordadas por el líder en cuestión, su estilo de dirección se ajusta a los cambios de una nueva era donde la conciencia y el humanismo se erigen hacia el pináculo de la columna orgánica en la gestión gerencial estratégica.

Finalmente, el nuevo siglo, y esta nueva era de la conciencia, dejan atrás quizás, una que fuera mucho más vertiginosa, convulsiva, agresiva, discriminadora, la era de la información, en donde todo acontecía tan rápidamente que las organizaciones y quienes la ingresen no podían permitirse tomar el tiempo de experimentar emoción alguna. Actualmente, las competencias emocionales, como flexibilidad, percepción, capacidad de motivar grupos, resultan ser factores de provecho, indistintamente que se tratare del sector público o privado, pues las emociones pueden encontrar lugar en el núcleo de cualquier tipo de negociación.

\section{5.- REFERENCIAS}

Argandoña, A. (1999). Ética en el liderazgo empresarial ante los retos del siglo XXI. Documento de investigación número 401. Segundo congreso Portugués de ética empresarial. Universidad de Navarra. España.

Arteaga, A. y Ramón, S. (2009). Liderazgo Resonante según género. Revista Multiciencias, 9 (3), pp. 289295. Universidad del Zulia. Punto Fijo. Venezuela.

Buitrago, R. \& Portillo, P. (2014). El poder, las mujeres y su liderazgo ejercido en el sector público. Revista Fórum Humanes. 3(2). Pp. 45-59. Venezuela.

Buitrago, R. (2015). El liderazgo gerencial femenino, una propuesta a la industria farmacéutica. Revista CICAG. 12(2). Pp. 212-225. Venezuela.

Buitrago, R. (2016). Liderazgo ético como factor potenciador del marketing social hacia la innovación estratégica en la mercadotecnia moderna. Revista Marketing Visionario. 5(1). Pp. 72-87. Venezuela.

Caldeira, M. (2016). Liderazgo innovador para emprendimientos sociales en organizaciones sin fines de lucro. Revista CICAG. 13(1). Pp. 191-207. Venezuela. 
Calderón, D. (2004). Negociación Exitosa. Revista Visión gerencial, 3 (1), pp. 51-61 Venezuela.

Cantón, I. \& Arias, A. (2008). La dirección y el liderazgo: aceptación, conflicto y calidad. Revista de Educación. pp. 229-254. España.

Contreras, F. (2008). Liderazgo: perspectivas de desarrollo e investigación. International Journal of Psychological Research. 1 (2), pp. 64-72. Universidad de San Buenaventura. Medellín. Colombia.

Díaz, N. (2012). Ética, Negociación y Valor Compartido. Daena: International Journal of Good Conscience. 7(1). 5-12.

El Kadi, O. \& Martínez, L. (2015). Análisis del proceso de negociación y mediación del conflicto interno en siria. Revista CICAG. 12 (1), pp. 231-247. Venezuela.

Fernández, A., Seijo, C. \& Martín, F. (2010). Toma de decisiones éticas en la industria farmacéutica: retos y desafíos. Revista CICAG. 7(2). PP. 14-30. Venezuela.

Fernández, A. (2012). Gestión ética del talento humano para el bien común en la empresa. Revista CICAG. 9(1). PP. 17-35. Venezuela.

Fernández, L. (2012). La comunicación y la negociación como herramientas estratégicas en la gestión de las relaciones públicas. Revista Quórum Académico, 9 (2), Pp. 296 - 314. Venezuela.

Ferrer, J., Colmenares, F. y Clemenza, C. (2010). Un líder ético para el cambio: plataforma de gestión estratégica en Instituciones Universitarias. Revista de Ciencias Sociales. 16(4). pp. 642 - 653. Venezuela.

Galíndez, W. (2011). Liderazgo y valores éticos: aproximación al contexto gerencial en la UPEL IPB. 15(2). PP. 96-122. Venezuela.

González, M. (2008). Imaginación, ética y negociación. Revista Razón y Palabra [en línea] 2008, 13 (Mayo-Junio). [Fecha de consulta: 27 de Octubre de 2016] Disponible en: http://www.redalyc.org/articulo.oa?id=199520738009.

Kadi, O. \& Acevedo, E. (2014). Liderazgo ético frente a la diversidad cultural dentro de las organizaciones con régimen disciplinario. Revista Económicas. 35 (2). Pp 75-88. Venezuela.

Meza, R. D. J. M., \& Olmos, R. E. (2014). Empowerment, el liderazgo e innovación en empresas de servicios, como ventaja competitiva en medianas empresas del municipio de Tecomán, Colima, México. En Desarrollo Gerencial Revista de la Facultad de Ciencias Económicas Administrativas y Contables de la Universidad Simón Bolívar - Colombia. 6(2). Pp. 72-97. 
Moreno, V \& Torres, H. (2008). Liderazgo resonante en la administración pública. Revista CICAG, 4 (2), Pp. 71 - 76. Venezuela.

Nava, D., Seijo, C. \& Mier, C. (2014). Inteligencias múltiples: característica congruente del liderazgo ético en entidades financieras. Revista Praxis. 10. PP 91 - 99. Venezuela.

Núñez, M.; Salón, J.; Romero, G. \& Rosales, V. (2009). Inteligencia emocional e intuición como plataforma en el manejo del conflicto y negociación. Revista Multiciencias. 9 (3), pp. 259-266. Venezuela.

Parra, E., Rojas, L. y Arapé, E. (2008). Comunicación y conflicto: El arte de la negociación. / www.revistanegotium.org.ve 10 (4). Pp. 17-35. Venezuela.

Portillo, I. \& Buitrago, R. (2015). Liderazgo cuántico como estrategia gerencial innovadora en organizaciones del sector privado en Hispanoamérica. En Desarrollo Gerencial Revista de la Facultad de Ciencias Económicas Administrativas y Contables de la Universidad Simón Bolívar Colombia. 7(2). Pp. 63-80.

Sabino, C. (2006). Los caminos de la ciencia: una introducción al método científico. Buenos Aires. Lumen-Humanista.

Sierra, R. (2010). El método investigativo. Venezuela. Editorial Suramérica.

Tocón, Susana. (2014). Un líder resonante. Dedica. Revista de educação e humanidades. 6, pp. 261-271. Brasil.

Velásquez, L., Guaiquirima, C. \& Seijo, C. (2011). Ecoliderazgo ético para una nueva gestión pública. Revista CICAG. 8(2). Pp. 13-30. Venezuela.

Vicuña, L.; Hernández, H.; Paredes, Mildred., \& Ríos, J. (2008). Elaboración del test de habilidades para la gestión en la negociación de conflictos. Revista IIPSI. 11 (2), pp. 183 - 200. Perú.

Zarco, V. \& Rodríguez, A. (2005). Ética y responsabilidad social en las organizaciones actuales. Revista Internacional de Ciencias Sociales y Humanidades. SOCIOTAM. 15(2). pp. 185-203. México. 